harmonics and the scale are treated of, and I am not surprised that its author cannot understand the numerical basis of Colin Brown's Just Intonation Harmonium.

The strict harmonic chords of the seven notes of the scale, including only sounds in the scale of $\mathrm{C}$, and excluding all approximations, are these :-

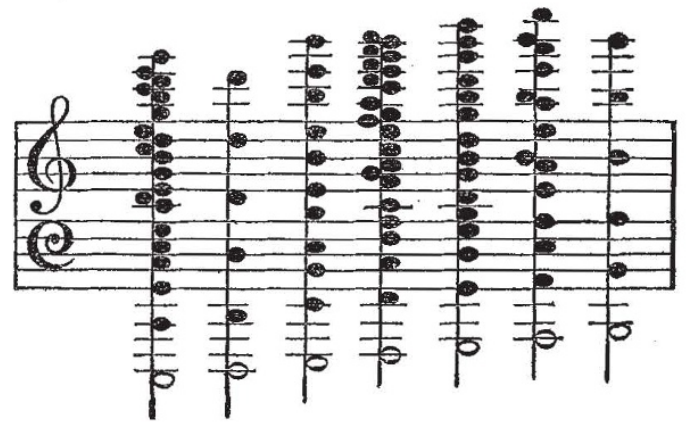

Here it will be observed that all the tones of the scale are harmonics of $\mathrm{F}$ and of that note only (a circumstance first pointed out by Colin Brown). I do not admit that $\mathrm{F}$ and $\mathrm{A}$ are notes interposed in the scale of $\mathrm{C}$.

Ordnance Survey Office, Southampton, February 8

\section{Protective Mimicry among Bats}

I HAVE read with much interest the remarks of Dr. S. Archer in Nature, vol. xv. p. 3r3, on the habits of Rynchonycteris naso, Wied. (= Proboscidea saxatilis et rivalis, Spix.), as they quite agree with notes on the same species made by me when travelling some years ago in British Guiana.

This is not, however, the first published notice of protective mimicry among bats. In my "Monograph of the Asiatic Chiroptera" (1876), I have referred to the peculiar markings of the wing and interlemoral membranes in Kerivoula picta, Vesper. tilio formosus, and $V$. Welwitschii, which are coloured on the same plan although these species are related in no other respects, and have stated that I believe these markings to be the result of "protective mimicry." Of one of the two first-named species, Mr. Swinhoe remarks :- "A species of Kerivoula allied to $K$. picta and $K$. formosa, was brought to me by a native. The body of this bat was of an orange brown; but the wings were painted with orange-yellow and black. It was caught, suspended head downwards, on a cluster of the round fruit of the Longan-tree (Nephelium longanum). Now this tree is an evergreen; and all the year through some portion of its foliage is undergoing decay, the particular leaves being, in such a stage, partially orange and black. This bat can, therefore, at all seasons, suspend from its branches, and elude its enemies by its resemblar.ce to the leaf of the tree. It was in August when this specimen was brought to me. It had at that season found the fruit ripe and reddish-yellow, and had tried to escape observation in the semblance of its own tints to those of the fruit."

A familiar instance of what appears to be "protective mimicry" occurs in the species of the genus Pteropus (Flying foxes of European residents in India). These, the largest of al bats, measuring, on an average, nearly one foot in length with an expanse of wing of from four to five feet, are, from their large size, very conspicuous objects even when the wings are closed, and easily seen from the ground when hanging from lofty trees. With very few exceptions these bats have the iur of the back of the head and of the nape of the neck and shoulders of a more or less bright reddish or bright buff colour, contrasting strongly with the dark brown or black fur of the back. At first sight it might appear that this remarkable contrast of colours would render the animal more conspicuous to passing enemies, and consequently more subject to their attacks when hanging in a semi1orpid condition. But any one who has seen a colony of these bats suspended from the branches of a banyan tree, or from a silk cotton tree (Erodendron orientale), must have been struck with their resemblance to large ripe fruits, and this is especially noticeable when they hang in clusters from the leaf-stalks of the cocoa-nut palm, where they may be easily mistaken for a bunch of ripe cocoa-nuts. Hanging close together, each with his head bent forwards on the chest, his body wrapped up in the ample folds of the large wings, and the back turned outwards, the

$$
\text { x Proc. Zool. Soc., 1862, p. } 357 .
$$

brightly coloured head and neck is presented tó view, and resembles the extremity of a ripe cocoa-nut, with which this animal also closely corresponds in size. ${ }^{1}$

The much smaller species of Cynopterus and Macroglossus, which feed on the fruit of guavas, plantains, and mangoes, re. semble these fruits closely in the yellow colour of their fur and in their size, so that it is very difficult to detect one of these bats when suspended among the leaves of any of these trees.

The resemblances, however, between these frugivorous bats and the fruits of the trees on which they roost, may be accidental, and, in the present state of our knowledge, we would scarcely be justified in setting them down as the result of "protective mimicry," though there can be little doubt that, to whatever cause due, they aid in concealing these animals from the attacks of enemies.

I could adduce other instances of what appear to me to be cases of "protective mimicry" among bats, but my letter has already much exceeded the limits intended by me when I com. menced it, and I must reserve my remarks on the peculiar posi. tion of Rynchonycteris naso when resting on a perpendicular plane surface for another communication.

G. E. DoBson

\section{Sense of Hearing in Birds and Insects}

IN respect to "The Sense of Hearing in Birds," the habit of pattering with the feet while seeking food, which is common to many worm-eating birds, seems to preclude the idea that such birds at least depend to any great extent upon their powers of hearing. Gulls frequently tread or patter with their feet while seeking food. The object being clearly to discover, from some slight movement, the whereabouts of their hidden prey. Plovers, doubtless with the same object, vibrate one foot rapidly with tremulous motion on the ground. Now the plover is essentially a worm-catching bird, more so even, probably, than the thrush. light-footed, active yet stealthy in its movements, quick-sighted, and certainly quick of hearing, the plover, when feeding, runs a little way, like the thrush, then stops, with head erect, looking intently ; listening it might well be thought but for the tremulous motion of its foot. The plover, at such time, trusts without doubt to sight and not to its sense of hearing.

It is true that the thrush has not this trick of pattering with the foot. It is true also that it has, while seeking food, very much the look of listening attentively. The largeness of its eye and comparatively small development of its ear incline me, however, to believe with Mr. McLachlan (NATURE, vol. xv. p. 254), that the thrush also depends when feeding more on its power of sight than on its sense of hearing.

C. J. A. MEYer

\section{THE ATMOSPHERE OF THE ROCKY MOUNTAINS 2}

$A$ NYONE who observes with a large telescope soon becomes aware of the great obstacle atmospheric undulation offers to the pursuit of astronomy, particularly in the application of photography and the spectroscope. During two years when I photographed the moon on every moonlight night at my observatory, ${ }^{3}$ there were only three occasions on which the air was still enough to give good results, and even then there was unsteadiness. Out of $\mathbf{r}, 500$ lunar negatives, only one or two were really fine pictures. A letter which the late Mr. Bond wrote to me states that in seventeen years he bad never met with a perfectly faultless night at the Cambridge Observatory.

Such facts naturally cause astronomers to consider whether it is not possible to diminish "atmospheric disturbances, and have led to the celebrated expeditions of Prof. Piazzi Smyth to the Peak of Teneriffe, and Mr. Lassell to Malta. Theoretically it would seem that the only complete solution is to ascend high mountain ranges or isolated peaks, and leave as much as possible of the air below the telescope.

Having had occasion during the months of August and September, 1876 , to go on a hunting trip with two distinguished officers of the United States Army into the Rocky Mountains

I In a note to Sir James Emmerson Tennent's "Ceylon." Mr. Thwaites remarks :- "These bats (Pteropus medius) take possession durng the day

of particular trees, upon which they hang like so much ripe fruit." tains, made at Elevations of from 4,500 to $11,0 c 0$ feet, in Utah, Wyomin Territory and Colorado." By Henry Draper, M.D., Professor of Analytica Chemistry and Physiology in the University of New York. Communicated by the author.

3 Prof. Henry Draper's observatory is at Hastings. on-Hudscn, vear New York; latitude $40^{\circ} 59^{\prime} 25^{\prime \prime}$, longitude $73^{\circ} 52^{\prime} 25^{\prime \prime}$; elevation above the sea, 22 feet. 
and Wahsatch range, I thought it desirable to carry a telescope, with a view of ascertaining whether there would be sufficient inducement to return with my I2-inch achromatic or 28-inch reflector, and make a prolinged stay.

A.s it was not feasible to take an instrument of any great size, I contented myself with a small achromatic of unusual excellence. Though of only $\mathrm{I}_{\frac{1}{4}}$ inches aperture, it bears a power of 60 completely, and I think would carry roo. It was provided with a short brass tripod, holding an altitude and azimuth movement, giving both steadiness and smoothness of action. The eyepiece was capable of adjustment by a rack and pinion, and the object-glass was so arranged in its cell as to be free from injurious compression. This little lens stands the severe tests invented by Foucault, and in spite of its size is capable of doing good work.

In such observations on the atmosphere as those proposed during this trip, it is obvious that there are mainly two points to be considered : (I) freedom from tremor, and (2) transparency. A station combining both is most desirable, but a marked predominance of steadiness gives special advantages for celestial photography, while increase of transparency, even if accompanied by unsteadiness, is of value in eye observations. I had been led to suppose from conversations with Government officers and persons connected with the geological and geographical surveys of the territories, that the Wahsatch range, which is intermediate between the Sierra Nevada on the west and the true Rocky Mountains on the east, would offer the greatest advantages. This supposition turned out to be altogether incorrect, though it might have been argued that a high range flanked at a distance on either side by other higher ranges should have given the maximum chance for cloudless and still skies.

We first went to Salt Lake City, which, according to the Casella aneroid I carried, is at an elevation of 4,650 feet above the sea. It lies at the foot of the Wahsatch range. At eleven o'clock on the evening of arrival, August 25, I took some observations from the hotel after carefully centring the object-glass. Saturn looked about the same as on an ordinary night at my observatory. Capella, which was just clear of the house-tops across the street, twinkled as badly both to the naked eye and in the telescope as I have ever seen it at the sea-level. Lieut. Warren, of Camp Douglas [a military post near the city] said there had been a heavy rain the week previous, and the air was more moist than usual. The sun set among just such a bank of clouds as we are accustomed to see in New York. I was somewhat prepared for a tremulous condition in these high regions, because, the preceding night, having stopped for a few nights at Fort Steele, on the Union Pacific Railroad, I perceived that Antares twinkled very much, though we were nearly 7,000 feet above the sea.

However, in order to make a thorough trial it seemed best to ascend one of the high peaks of the Wahsatch, and accordingly the Red Butte was selected. The peak proved to be 7,350 feet high. Though it was quite clear when we started, clouds gathered in every direction as the sun went down, and at nightfall the sky was entixely overcast. Moreover, the wind blew so strongly that it was necessary to retire over the brow of the mountain, and eventnally we returned to Camp Douglas. At this point, 5,250 feet above the sea, and about 600 feet higher than Salt Lake City, the telescope was set up to take advantage of some breaks in the clouds, through which the moon, Antares, $\zeta$ Ursæ Majoris, and Jupiter appeared. With a power of only twenty the twinkling was surprisingly great; $I$ do not remember ever to have seen it worse with my large instruments.

These results led to an examination into the meteorology of Salt Lake City, so as to find out the rainfall and its distribution and the percentage of cloudy days.

It appears that the average annual rainfall for the past five years is $188^{40}$ inches. There is no perfectly dry month, the nearest approach being during the summer. The cloudy dry days are 194 per annum, the disposition being similar to the rinfall.

A former pupil of mine, and graduate of the University, Dr. Benedict, informed me the Mormons believed the rainfall had much increased since their community had settled in Utah, and this seems to be borne out by the statement that whereas formerly three gallons of Salt Lake water produced on evapora tion one gallon of salt, it now takes four gallons to produce the same quantity.

For these reasons it is doubtful whether there would be enough advantage in bringing a large telescope to this region to make it worth while to encounter the labour and expense.
On August 30, having taken an escort, we moved south from Fort Steele, latitude $4 \mathrm{r}^{\circ} 48^{\prime}$. longitude $107^{\circ}$ o $9^{\prime}$, along the North fork of the Platte River, into the main range of the Rocky Mountains. During the fifteen days' expedition there were only two nights on which we saw clouds enough to prevent astro. nomical working, and only one thunderstorm of any moment took place in our immediate vicinity; about one quarter of an inch of rain fell. The sky was rarely perfectly free from clouds, and many local thunderstorms occurred about the higher peaks, but they seldom extended to the plateaus below.

September $\mathbf{I}$ and 2 our camp was 8,900 feet above the sea in the vicinity of mountains rising 10,000 and I I,000 feet. These peaks seemed to be nearer than they really were, for the tran. sparency of the air causes estimates of distance to be deceptive. From the top of one I subsequently saw the Seminole Mountain, which was 150 miles distant; it did not appear to be fifty miles away. The night of September I was quite clear, with very little cloud, and the atmosphere remarkably tranquil. Antares, when near setting, hardly twinkled at all, and Arcturus in the telescope, exhibited four diffraction rings unbroken by flickering. The central disc was as hard and sharply defined as the pin-hole in the lamp-screen $I$ am accustomed to use in testing specula and lenses. I looked for the companion of Polaris, but partly on account of the nearly full moon, and partly from the thickness of the diffraction-rings, I could not be sure of it. The moon was perfectly steady; with a power of sixty there was no trace of twinkling at the terminator. I tried to see Titan, the largest satellite of Saturn, but did not succeed. At the time it was not certain whether this failure was due to the position of Titan with relation to Saturn, or whether it arose from the blinding effulgence of the moon. Capella was perfectly steady, though there was a slow change of colour from bluish to reddish, occupying about a second.

The succeeding night, at nine o'clock, though the sky was mostly covered with cumulus clouds in motion southward, I was astonished to find the terminator of the moon absolutely free from twinkling and Arcturus down among the tops of the dead aspen trees as steady as possible. The four diffraction rings round the central disc were not perfectly circular, but that was the fault of the lens. Every defect of centring or of surface and any vein in the glass comes out even more clearly than in the work. shop examinations, because, while the air is as steady, the light is far more iutense.

I am certain, if a large telescope could be brought here and maintained against the furious winds, great results might be attained if there is much of this weather. But this particular place is difficult of access, and possibly no better than other situations on the line of the railroad. The sky is not as black as I had expected; it is rather of a light blue, though the full moon makes much difference.

On several other nights, in both lower and higher places, I made observations, but never saw the combination of steadiness and transparency again. On the plateaus at the foot of the mountains and away from the groves of quaking aspen trees and pines, the sun sends down scorching rays all day long on the alkali plains, where only sage plants are sparsely scattered, and even on horseback one can see the heated waves rising from the ground. The air is far from being moist, for the lips are apt to crack and bleed, and the mucous membrane of the nose is parched. When the sun sets the ground rapidly radiates, and we frequently had by morning one quarter of an inch of ice in our vessels of water standing outside the tents. These plateaus are on an average about 7,250 feet above the sea. The mere fact of broken ground and wooded surroundings does not, how. ever, suffice to produce, even at this season, a tranquil air; for when we rode over the Rocky Mountains, along the margin of perpetual snow, to the head-waters of Snake River, and camped at Trout Lake, nearly 10,000 feet high, though the air was exceedingly transparent, it was very unsteady. I rose at $4 \mathrm{~A}, \mathrm{M}$. to see Venus, and her splendonr was so great that it led to a most delusive estimate of her apparent size. Occasionally, during clear frosty weather in midwinter, a night of similar characteristics is seen at my observatory. On such an occasion I obtained, at the principal focus of the $15^{\frac{1}{2}}$-inch reflector, a photograph of the moon near her third quarter in less than a second.

The officers of Fort Steele and the guides say it would be impossible to do any astronomical work in this region from the middle of October till the middle of May, that is, for seven months. The fierce winds, heavy falls of snow, and intense cold would be unbearable. Even in the beginning of September 
we needed large camp-fires in the morning and evening. Our camp at Trout Lake could only be reached for six weeks in summer on account of the depth of snow in the fallen timber.

On the whole, it may be remarked of this mountain region, that the astronomical condition, particularly for photographic researches, is unpromising. In only one place were steadiness and transparency combined, and only two nights out of fifteen at the best season of the year were exceptionally fine. The transparency was almost always much more marked than at the sealevel, bui the tremulousness was as great, or even greater, than near New York. It is certain that during more than half the year no work of a delicate character could be done. At the end of August, in sheltered positions, and in good tents, we slept under half a dozen thicknesses of blankel, and only partially undressed. Such a degree of cold distracts the mind and numbs the body. Apparently, therefore, judging from present information, it would not be judicious to move a large telescope and physical observatory into these mountains with the hope of doing continuous work under the most favourable circumstances.

\section{TESTIMONIAL TO MR. DARWIN}

MR. DARWIN has received as a testimonial, on the II occasion of his sixty-ninth birthday, an album, a magnificent folio, bound in velvet and silver, containing the photographs of $\mathbf{1 5}_{54}$ men of science in Germany. The list contains some of the best known and most highly honoured names in Europe. He has likewise received on the same occasion from Holland an album with the photographs of 217 distinguished professors and lovers of science in that country. These gifts are not only highly honourable to Mr. Darwin, but also to the senders as a proof of their generous sympathy with a foreigner; and they further show how widely the great principle of Evolution is now accepted by naturalists.

A German correspondent informs us that the German album bears on the handsome title-page the inscription "Dem Reformator der Naturgeschichte, Charles Darwin."

MICROSCOPICAL INVESTIGATION OF SANDS $A N D$ CLAYS

THE anniversary address of the president, $\mathrm{Mr} . \mathrm{H}$. C. Sorby, F.R.S., at the Royal Microscopical Society on Wednesday, March 7, consisted mainly of an attempt to treat in a systematic manner the application of the microscope to the study of the mineral constituents of sands and clays. The various organisms found in such deposits have been much studied by Ehrenberg and other microscopists, and of late years much attention has been directed to the structure of igneous and other hard rocks, more or less allied to them, which can be cut into thin sections ; but comparatively little attempt has been made to investigate the ultimate constitution of loose sands, muds, and clays.

The scope of this subject, as treated by the author, included the identification of the true mineral nature of the various particles, and the determination of the nature of the rock from which they were originally derived; the chief aim being to trace back the history of the material to the furthest possible extent.

After describing the manner in which the different kinds of deposits should be prepared, examined, and mounted as permanent objects, the author treated at some length on the conditions necessary for satisfactorily seeing the various particles with moderate or very high magnifying powers, and for observing their microscopic structure and optical characters. The particles of clay and the fluid-cavities in the grains of sand are often so minute as to task the power of the microscope to the fullest extent, and some indeed are so small that their perfect definition may perhaps be impossible by any means at our command. It was shown that the condi-

$$
\text { Abstract by the author. }
$$

tions under which many of the objects are visible are such that with highly convergent light and object-glasses of large aperture no dark outline is possible, and therefore they are quite invisible; but become quite distinct when the aperture is reduced to a moderate and appropriate amount. For this reason object-glasses of comparatively small aperture are far the best, since the focal point being further from the front lens, very high powers can be used in cases which are beyond the reach of lenses of large aperture.

The author then went into much detail to show the character of the grains of quartz, mica, and other minerals derived from the decomposition or breaking up of various crystalline rocks, and showed that on the whole there are many characteristic differences between the material derived from granitic and schistose rocks-this difference consisting mainly in the form, internal structure, and optical characters of the various constituent grains; the general conclusion being that a careful study of sands, muds, and clays enables us to form a very satisfactory opinion as to whether they were derived mainly from granitic or schistose rocks, or from a mixture of the two in some approximately definite proportion. It was also shown that the shape of the particles as originally derived from their parent rock is sufficiently definite and characteristic to enable us to form a very good opinion respecting the amount of subsequent mechanical or other change.

Applying those principles to the study of particular typical cases, it was shown that the coarser grained British sandstones have been mainly derived from granite rocks, of a character somewhat intermediate between. those of the Scotch Highlands and Scandinavia. Some of these sandstones consist of grains which have undergone scarcely any wearing, and are as angular as those derived directly from decomposed granite, and are thus totally unlike the blown sand of the deserts, which are worn into perfectly rounded grains.

The finer grained sands are no less angular than the coarse, and have not been derived from the wearing down of larger fragments, but have resulted from the separation of the small from the large grains by the action of currents. Though some fine-grained sand-stones have been mainly derived from granitic rocks, yet, on the whole, the small particles of quartz have more commonly been derived from the breaking up of schistose rocks. Clays and shales consist to a great extent of particles identical in all their characters with those derived from the decomposition of felspars and other minerals which undergo a similar change. As a general rule we meet with many grains of sand even in clays chiefly consisting of extremely minute granules, which can easily be explained by the remarkable manner in which such material, when suspended in water, collects into small compound grains, which subside at a rate quite independent of what would be the velocity of subsidence of the separate particles if they were detached.

The conclusions derived from a study of the characters of the separate grains are confirmed by the occurrence of what may be truly considered to be grains of granite or mica schist. We also in some cases meet with grains sufficiently large to show the characteristic structure of the still more complex rocks of which they are composed. Thin sections of some of the oldest slates in Wales are thus as it were a perfect museum of specimens of the rocks existing at a still earlier period, broken up and worn down into the sands which formed these very ancient slates.

Jn order to establish these various conclusions it would be necessary to enter into a large amount of detail, but perhaps what has been said may suffice to indicate the general line of inquiry, and to show that by making full use of every microscopic means, it is possible to learn many important facts from such very unpromising mate: rials as sands and clays. 